\title{
The Role of Technical Analysis Indicators over Equity Market (NOMU) with R Programing Language
}

\author{
Mohammed A. Al Ghamdi \\ Computer Science Department \\ Umm Al Qura University, Makkah City, Saudi Arabia
}

\begin{abstract}
The stock market is a potent, fickle and fastchanging domain. Unanticipated market occurrences and unstructured financial information complicate predicting future market responses. A tool that continues to be advantageous when forecasting future market trends in a global aspect is correlation analysis to significant market events. Data analysis can be used for the difficult task of making stock market forecasts in case the stock price rises or fall. A high number of automated exchanges in the stock market are done with advanced prognostic software. Data analysis is centered on the main idea that previously recorded data is used to predict future patterns. This advancement is aimed speculators in pinpointing hidden data in real evidence that would give them some financial foresight when considering their ventures of choice. Data analysis can be applied in order to predict the rises and falls of stocks in the future. This paper aims to critically investigate, develop and judge the different systems that predict and assess future stock trades as these systems have their own various process to foretell the fluctuations in the costs of stocks. Several different technical analysis indicators have been applied in this study including; Chaikin Money Flow (CMF), Stochastic Momentum Index (SMI), Relative Strength Index (RSI), Bollinger Bands (BBands), and Aroon (Aroon) indicator. The experiments have been conducted using $\mathbf{R}$ programing language over two companies' real-world datasets obtained for two years from Saudi stock market (NOMU) which is a parallel stock market with lighter listing requirements that serves as an alternative platform for companies to go public in the main market. To the best of our knowledge, this is the first work to be conducted in NOMU stock market.
\end{abstract}

Keywords-Data mining; data analysis; $R$ programing language; Chaikin Money Flow (CMF); Stochastic Momentum Index (SMI); Relative Strength Index (RSI); Bollinger Bands (BBands); Aroon indicator

\section{INTRODUCTION}

The equity market which is known popularly as stock market is defined as a platform where stock's trading take place for specific listed companies. The economy has a direct effect on the performance of the stock market. It is a variable system with little defined parameters that making it challenging to accurately explaining them. Speculators have continuously tried to understand how stock prices can be foreseen and forecasted in order to make their sales and investments on the market. In order to achieve this goal, scientists used strategies of key examination- in which data related to the industry, macroeconomics, and important figures are used to make exchanging rules. Technical analysis methods usually are conducted using stock volume, price, and historical data by several researchers. Techniques used to estimate and extrapolate stock volume, prices and movements are what is referred to as technical analysis.

The supposition that history is repeated and that analyzing historical pricing information to predict upcoming market advances is what this revolves around. Hence it can be expected that profit can be made by making use of existing price trends and tendencies.

The stock market is very erratic and indeterminate. There will be stocks that hardly undergo drops and there will be some that undergo major price hikes, and some will not change very much.

The data used in this paper are the historical prices of two Saudi Arabia Stock Exchange-listed companies in (NOMU) over two years.

Investors support the four ensuing guiding principles:

- When investing in stocks, don't follow the herd.

- Until you understand its composition, do not invest in s tock.

- Do not trust the rumors, but first, confirm the facts.

- Determine your personal risk appetite before investing in stock by considering an acceptable risk-reward ratio.

The stock market is a platform that made it easier for individuals as well as companies to trade their stocks at an agreed price of listed companies. Listed companies are defined as the companies that their shares are offered for public trading by stock exchanges. Stock markets are steadily becoming central to national and global economies as they can greatly affect them with the rises and falls of stocks. It is known that a key of countries economic power is their stock markets. There can be one or more stock markets in each region or country depends on the market size, and numbers of companies. 
The authorities of the stock market focus on finding financial frauds in the market and investors usually check with investment portfolio management and stock market prices. In order to gain maximum revenue from the market investors should predict the fall and rise of prices so they can invest accordingly.

The most critical point here is to identify potential stock rises and falls so that profits can be earned in a relatively sustainable manner. Stock market data such as price and volume play crucial roles in studying the behavior of the market. The price of the stock market consists of four main prices, i) open price which is determined based on opening auction that is conducted between 9:30 am to 10:00 am, where investors issuing their trade orders, then the fair price for the open price is selected [1], ii) close price which is computed in the same way that open price is calculated but the time is different from 3:00 pm to 3:10 pm [1], iii) high price is the highest trading price during the day, iv) low price is the lowest trading price in the day. Stock market' volume is described as the number shares in specific time. A correct approach to these parameters would allow for substantial investments to be made.

There are two common tools that can be implemented in order to support investors decision in the stock market [2], [6], [3], and [4]. Firstly, fundamental analysis where the focus is on the evaluation process of the intrinsic value of a security [3]. Fundamental analysis is performed based on three main phases known as economy, industry, and company (EIC) and each of which has his own factors and indicators to be analyzed and studied well by investors [4]. Interest rate, inflation rate, and unemployment rate play crucial roles in the development of any national economy [6]. Industries' competitive analysis and life cycle analysis of industry are two factors related to industry analysis [4]. Investors deal with the different factors that have affect for the company performance such as company business concept and financial statement for company [6].

The second aspect helps investors in enhance their decision for investments at stock market are known as technical analysis. Technical analysis is also known as "Charting' as it is based on using charts for the past prices movement in order to forecast the future changes of the proposed prices [5]. The focus in technical analysis is only on analysis the stock price and volume in order to predict the future price change [2]. This is affected by the demand and supply in the stock market, as if the demand is at high level then the price will be higher, and when the supply is at high level the price will be lower. The study in [7] has defined three main premises affect the technical analysis; i) discount and built-in any information affect the price of stock, ii) tendencies is essential in determined prices, and iii) the repeated movements of prices are often.

The strategy of the technical analysis is to employ mathematical calculations in order to detect the stock prices activities during proposed periods of times. Technology can be applied in such matter in order to enhance the behavior of the different of the indicators related to the technical analysis. $\mathrm{R}$ is a programming language that has been created by Ross
Ihaka and Robert Gentleman in 1991 in Statistics Department at Auckland University, New Zealand [8]. Then in the announcement of the $\mathrm{R}$ language to the public has been made. $\mathrm{R}$ is an open source programing language and applied mainly in statistical computing area of research. It is free and also run on all standard computing platform. Added to this the user community of $\mathrm{R}$ is highly active, and it has been using by well-known companies such as Microsoft, Google, IBM, and Oracle.

The rest of the paper is organized as follow. Section II discusses the related works and Section III presents the methodology that is applied in this work. The results of experiments and discussion are presented in Section IV while conclusion is stated in Section V.

\section{Related WORKS}

Many important changes in the environment of financial markets have occurred over the last two decades. The development of powerful facilities for communication and commerce has expanded investors ' selection. The provision of stock returns is a significant financial topic that has attracted the attention of researchers for many years. It implies that in the past, basic information available to the public has predictive links with future stock returns. Therefore, several studies have focused on technical analysis and the use of advanced mathematics and science in such area of research.

Investors in stock market usually interrelate with different sources of information in order to maximize their benefit from trading in stocks. Stock market analysis is one of these ways that may support investors in making their decision [9]. Applying forecasting in stock market is considered as challenging task due to the intricacies of the market [10], [11] and [12]. However, forecasting has several different benefits for both sellers and buyers through helping in plan for upcoming events and providing information for allocating resources and determining the foreseen prices in future [13].

Applying forecasting models for stock market may help investors in making their decision through applying ARIMA approach which is beneficial also in stock market studies as in different real-world challenges such as education and health [13]. Several different technical analysis methods are applied in order to study the historical data of stock market for finding the hidden through applying 5 different techniques including; 1) Typical Price (TP), 2) Bollinger Bands (BBands), 3) Relative Strength Index (RSI), 4) Chaikin Money Flow (CMF), and 5) Moving Average (MA) [14]. The data of three Nigerian banks in the stock market has been studied and analyzed by applying data mining tools such as liner regression and moving average approaches [15]. The study confirms also that applying data mining methods over stock market shows beneficial return and help in increasing the investments on stock market.

Three technical indicators including; Stochastics Oscillator (SO), Relative Strength Index (RSI), and Moving Average Convergence-Divergence (MACD) have been applied in order to measure how beneficial to apply the predictive model built by applying these three indicators over chosen workload, and the results shows that SO, and RSI may improve the decision 
made by investors comparing with MACD. Auto Regressive Integrated Moving Average (ARIMA) model has been conducted over two datasets achieved from New York Stock Exchange (NYSE) and Nigeria Stock Exchange (NSE) in order to develop an extensive process of building stock price predictive, and the results show that applying such technical indicator could play crucial role in supporting investors decision in stock market [16].

The study in [17] has applied technical analysis methods in order to monitor and forecast the trends of the stock market. The data used for the study was for six months from January to June 2016.

On the basis of research, it has been found that there are limited studies conducted on the Saudi Stock Market alongside technical analysis Hence, the following objects are highlighted:

- To study the efficiency of applying technical indicators over Saudi stock market (NOMU).

- To build predictive model for Saudi stock market by using $\mathrm{R}$ programing language.

- To analyze the selected companies with technical indicators.

\section{METHODOLOGY}

Technical analysis indicators are grouped within four different categories [17]; 1) Trend indicators, 2) Momentum indicators, 3) Volatility indicators and 4) Volume indicators. Trend indicators are applied to measure the trend's direction and strength to produce average value, where the buy mode is activated when the price moves above the average and sell mode is detected when the price goes below the average value. The speed of price movement can be identified by using the momentum indicators. Volatility indicators detect the prospect points where the direction of the market may change. The total amount of trading occurs within given period of time is represented by Volume indicators.

In this paper, five technical analysis indicators have been applied on the proposed data; i) Chaikin Money Flow (CMF) Volume indicator, ii) Stochastic Momentum Index indicator (SMI) - Momentum indicator, iii) Relative Strength Index indicator (RSI) - Momentum indicator, iv) Bollinger Bands indicator (BBands)-Volatility indicator, and v) Aroon indicator (Aroon) - Trend indicator.

This work aims to study the impact of the technical analysis indicators over Saudi stock market (NOMU). NOMU market is an alternative stock market where the requirements of the listed companies are lighter compared to the main Saudi market. The main aim of NOMU market is to support the sector of small and medium-sized companies by providing the sector with numerous funding resources in order to rise their revenues and profits. The stock trading in NOMU market opened on Sunday $26^{\text {th }}$ February 2017. The experiments in this work have been conducted over two datasets from real-world of two companies listed in NOMU market; 1) Al-Samaani Factory for Metal Industries and, 2) Arab Sea Information System using R language in R-Studio platform. R-Studio is cost-free and open source, and integrated development environment for $\mathrm{R}$ language. Where the user run its $\mathrm{R}$ scripts in a user-friendly environment. There are two editions from the R-Studio which is; i) R-Studio Desktop, ii) and R-Studio Server. In the desktop version the written program is run locally like other desktop application, where the server version allow user from accessing to remote Linux server through web browser in order to run the code. $\mathrm{R}$ in this work is applied through using TTR package which contains several essential functions that can be used for technical analysis [8].

\section{A. Chaikin Money Flow Indicator (CMF)}

The Chaikin accumulation distribution (AD) is the intrinsic factor of the Chaikin Money Flow indicator [18]. $\mathrm{CMF}$ indicator measures the total amount of money flow volume within selective period called buying and selling pressure. A move into positive zone indicates buying pressure, and selling pressure is indicated when the move occurs into the negative. The CMF indicator is calculated by dividing the total of accumulation distribution (AD) by the total of the volume within specific period (n). The formula (1) and (2) can be used to calculate the CFM indicator [18].

$C M F=\frac{\sum_{i=1}^{n} A D}{\sum_{i=1}^{n} \text { Volume }}$

$A D=$ Volume $* \frac{(\text { close price-open price })}{(\text { high price-low price })}$

In general, the buying pressure is stronger when the indicator value of $\mathrm{CMF}$ is more than zero (positive) and selling pressure is stronger when CMF indicator value is less than zero (negative).

\section{B. Stochastic Momentum Index Indicator (SMI)}

SMI was developed by William Blau based on the stochastic oscillator [20]. The values of SMI indicator has range between (+100) and (-100) [19].

The SMI indicator value is above zero when the closing price is more than midpoint and is below zero when the closing price is less than the midpoint.

Extreme values of SMI (high or low) indicate that overbought or oversold mode is detected. When the SMI rises above (-50), or when it crosses the signal line, a buy signal is generated. SMI is used by investors as a general trend indicator. In general, if SMI value more than $(+40)$ then the bullish trend is detected and if SMA value greater than (-40) a bearish trend is activated. The formula (3), (4) and (5) are applied in order to calculate SMI value.

$$
\begin{aligned}
& c m=\text { close price }-\left(\frac{\text { highest high value }+ \text { lowest low value }}{2}\right) \\
& S M I=100 *\left(\frac{\mathrm{cm}}{\text { (highest high value-lowest low value }) / 2}\right) \\
& \text { Signal }=E M A(S M I)
\end{aligned}
$$

\section{Relative Strength Index Indicator (RSI)}

RSI indicator has been developed to measure both the price movements speed and its change as well. The range of the RSI indicator is between 0 to 100 . Overbought case is indicated when the value of the RSI indicator above $(+70)$, 
and oversold case occurs when RSI indicator value below the value of (30) [21]. In general, overbought state is indicated when the value of the RSI indicator is more the value of 70 . On the other side when the value of the indicator is less than 30 the mode of the market is in oversold mode. RSI indicator is calculated by applying the equation (6).

$R S I=100-\left(\frac{100}{\left(1+\left(\frac{\text { average gain }}{\text { average loss }}\right)\right)}\right)$

\section{Bollinger Bands Indicator (BBands)}

A simple average moving band is the bases of the Bollinger Bands (BBands) indicator as the standard deviation calculation using SMA methods. This indicator is presented as a three lines group plotted on a figure where the middle band is the average moving of the stock prices, and the upper band is above the middle band in two standard deviations; the low band is below the middle band for two standard variations.

The top and bottom lines (bands) can show the volatility of the market. In other words, the market volatility is high when the space between these two lines are not close. The two bands become close together during when the market is less volatility. BBands is generally used as a guide, indicating potential reversals in trends. If current price breaks through Bollinger's bottom band, a buy signal will be considered. A sell signal is considered if current price breaks through the upper band.

Middle Band = SMA (price)

Upper Band =

Middle band $+($ Standard Deviation of price $* 2)$

Lower Band =

Middle band - (Standard Deviation of price $* 2)$

\section{E. Aroon Indicator}

Aroon is an indicator that has been developed in order to specify the status of the market whether it is trending or not. It also shows how strong the trend of the market if it is trending. The indicator tries to connect the price of the market with the time and it is range between 0 to 100. Aroon indicator has two separate indicators; 1) Aroon Up, and 2) Aroon Down, and these two indicators can be computed by using the equations (10) and (11), respectively.

Aroon Up Indicator $=$
$\left(\frac{\text { No. of Periods }- \text { No. of Periods since Highest High }}{\text { No. of Periods }}\right) * 100$

Aroon Down Indicator $=$

$\left(\frac{\text { No. of Periods }- \text { No. of Periods since Lowest Low }}{\text { No. of Periods }}\right) * 100$

\section{EXPERIMENTS, RESULTS AND DISCUSSION}

The proposed experiments have been conducted in this work over real-data for two companies (Al-Samaani Factory for Metal Industries Company and Arab Sea Information System Company) listed in the Saudi stock market (NOMU). The dataset was obtained for these two companies from $26^{\text {th }}$ February 2017 to $24^{\text {th }}$ February 2019 . The following subsections present the experiments results and discussion.

\section{A. Chaikin Money Flow Indicator}

CMF indicator was developed by Marc Chaikin. It is a volume-weighted average within specific period of accumulation and distribution as well. In general, when the $\mathrm{CMF}$ value is continuous above zero this means that there are buying operations. The sell operation is recommended when the CMF value is continuous below zero.

In R Chaikin Money Flow indicator can be executed by using $\mathrm{CFM}($ ) function, where the function has three arguments [22]. The first argument is the data object, and, in this case, it contains the high, low, and close prices (HLC), while the second parameter in the function is the volume related to the object data (volume). The last argument is the number of periods that is selected, and it is 2 in this experiment (n).

1) Al-Samaani factory for metal industries company: Fig. 1 presents the implementation of the CMF indicator over the first data set which is the data of Al-Samaani Factory for Metal Industries Company. At the beginning periods on this dataset shows that there are continuous buying operations as the CMF value is greater than zero (from $5^{\text {th }}$ to $13^{\text {th }}$ March 2017). Then the CMF goes down below the value of zero where the sell operations are detected (from $14^{\text {th }}$ to $15^{\text {th }}$ March).

2) Arab sea information system company: The experiments result from applying the CMF indicator over the data set of the Arab sea information system company is shown in Fig. 2. The figure shows that are several different crosses of the zero line within the used dataset. The figure also states that buying operations are active during the period as an example from $7^{\text {th }}$ March to $9^{\text {th }}$ April 2017. The operation of selling is detected during several times during the experiments (i.e. $6^{\text {th }}$ to $18^{\text {th }}$ June 2017 ).

\section{B. Stochastic Momentum Index Indicator}

SMI computes the distance between the close price of the stock and the median (midpoint) of the low or high prices with range between the values $(+100)$ and (-100). The value of SMI is positive if current close price is more than the median or the low/high range and vice versa. SMI is applied by the traders to detect the oversold or overbought modes in the proposed market. The experiments result from applying the SMI indicator over the used data sets in this work as shown in Fig. 3 and 4.

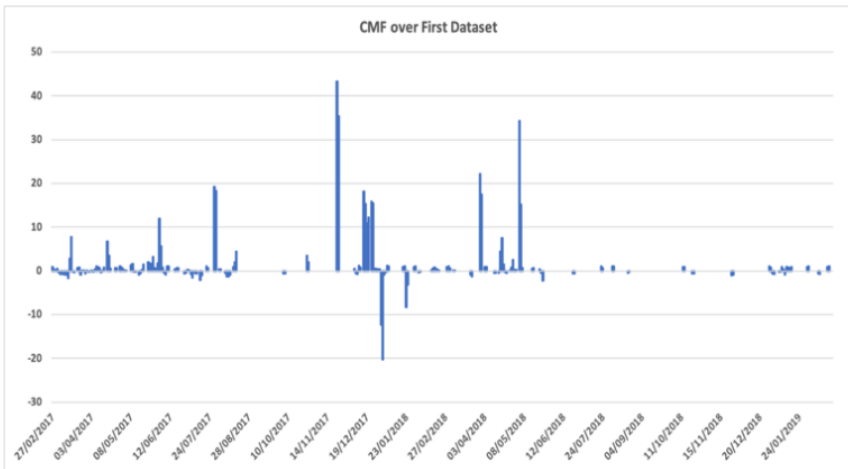

Fig. 1. Chaikin Money Flow Indicator Over First Data Set. 


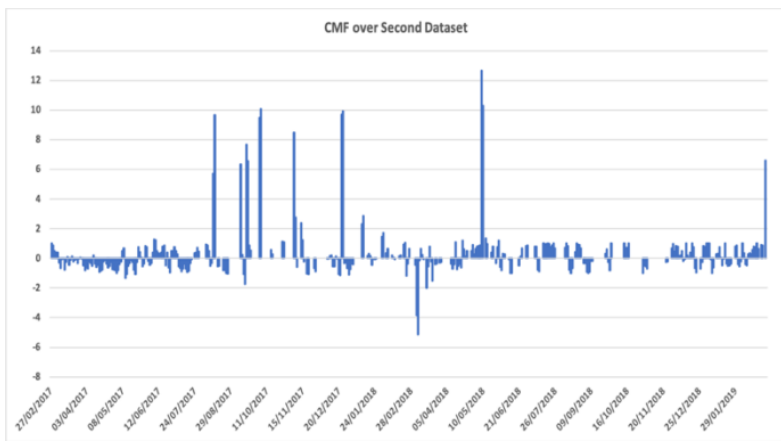

Fig. 2. Chaikin Money Flow Indicator Over Second Data Set.

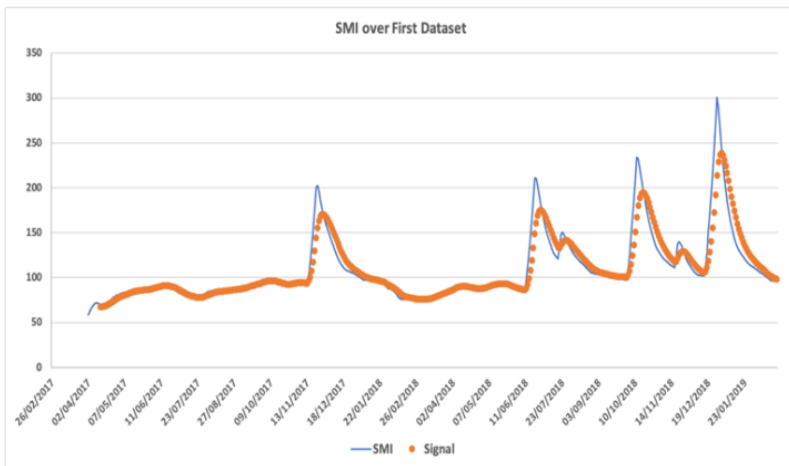

Fig. 3. Stochastic Momentum Index Indicator Over First Data Set.

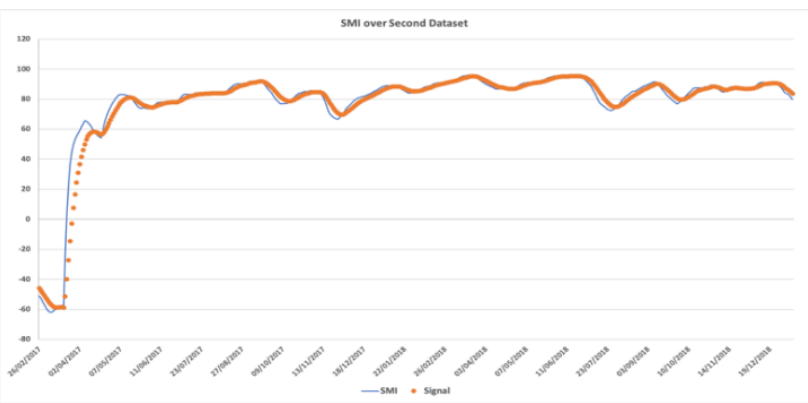

Fig. 4. Stochastic Momentum Index Indicator Over Second Data Set.

The SMI indicator can be applied in R by using SMI() function which is existing in TTR() package [22]. The function has multiple parameters and in this experiment 5 parameters are defined, and the rest left as in default. The first argument in the function is data object which is represented by the high, low, and close prices (HLC). The second parameter is the number of periods that is chosen, and it is 13 in this experiment. The third, fourth, and fifth parameters used in SMI() function are the numbers of periods for initial, number of periods for double smoothing, and numbers of periods for signal line, and they are valued by 13,2, and 9 respectively.

1) Al-Samaani factory for metal industries company: Fig. 3 presents the results from applying the SMI indicator over the first data set. It is clear that the SMI indicator values during these experiments always being over the value of +40 representing that the stocks are overbought. The figure also shows that the signal cross over SMI indicator in different occasions indicating bearish trend (see mid-November 2017, end June 2018, mid-October 2018, and end December 2018).
2) Arab sea information system company: The results from applying the SMI indicator over the second dataset are presented in Fig. 4. The stock market of the proposed company was in oversold mode as the value of the SMI was below -40 until the beginning of May 2017. After that the stocks market for the proposed company becomes stable for around three weeks (end of May 2017). Then it is converted to the overbought conditions as the SMI indicator values become more than +40 . The bearish trend can be pointed from the figure in some cases where the signal crosses below the signal line; for example, see at the beginning May 2017, end May 2017, beginning April 2017.

\section{Relative Strength Index (RSI) Indicator}

RSI was developed by J. Welles Wilder. It is applied in order to measure the change of the price movements and its speed. RSI calculates the ratio of the recent expanding value of the price movements to the absolute price movement itself, and it ranges between 0 and 100 .

The mode of the market is indicated as; i) overbought when the value of SMI indicator is more than 70, and ii) oversold if the SMI indicator value is less than 30 .

In $\mathrm{R}$ programing language the function $\mathrm{RSI}()$ is applied to execute the RSI indicator [22]. The function RSI() has several arguments including; 1) the price of the market, in this experiment the close price is selected to represent the price here, 2) the total periods selected to represented the moving averages for the selected price, and 14 periods has been selected in this experiment, and 3) other arguments that applied in specific situation.

1) Al-Samaani factory for metal industries company: The results from applying the RSI indicator over the first dataset is presented in Fig. 5. Several overbought modes have been detected in the following periods; i) end of December 2017, ii) end of January 2018, iii) end of December 2018, iv) From $22^{\text {nd }}$ January 2019 to $3^{\text {rd }}$ February 2019 , and v) from $12^{\text {th }}$ to $24^{\text {th }}$ February 2019.

The modes of oversold have been spotted in different several slots of time; from $10^{\text {th }}$ to $23^{\text {rd }}$ July 2017 , from $9^{\text {th }}$ to $13^{\text {th }}$ August 2017, from $17^{\text {th }}$ to $25^{\text {th }}$ October 2017, from $2^{\text {nd }}$ to $24^{\text {th }}$ July $2018,12^{\text {th }}$ August to $20^{\text {th }}$ November 2018.

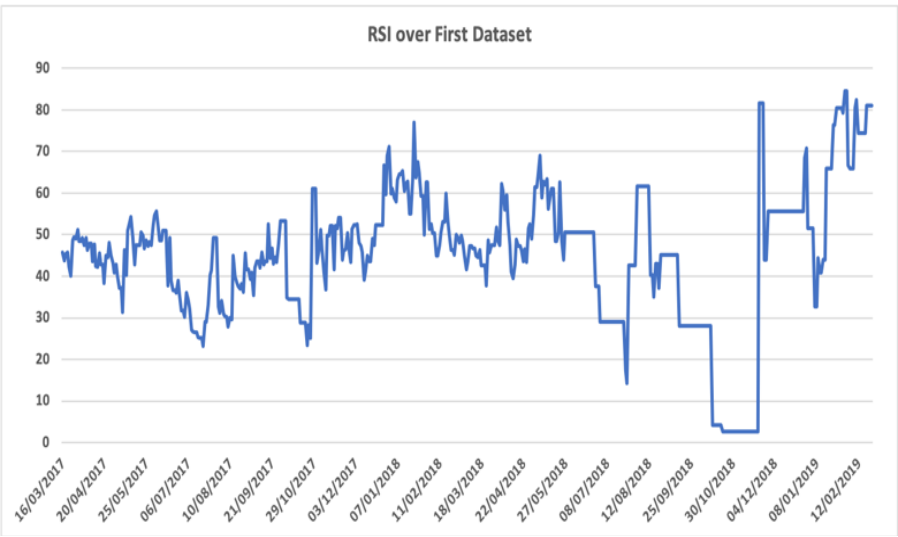

Fig. 5. Relative Strength Index (RSI) Indicator Over First Dataset. 


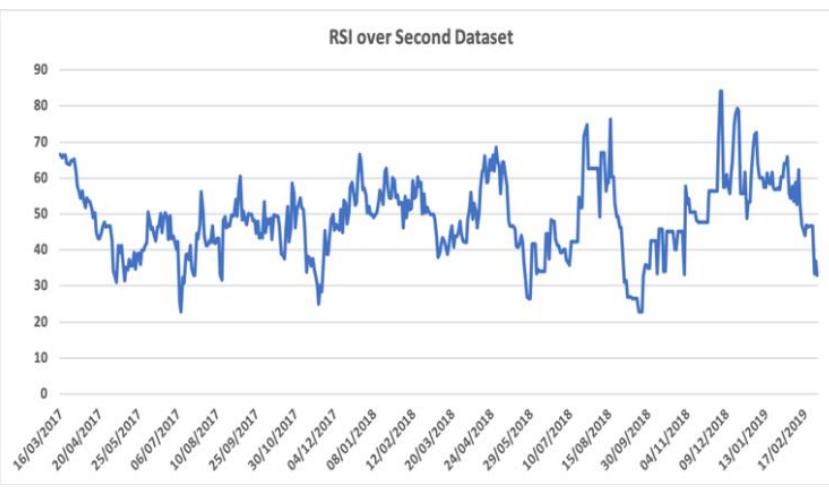

Fig. 6. Relative Strength Index (RSI) Indicator Over Second Dataset.

2) Arab sea information system company: Fig. 6 presents the results of conducting the RSI indicator over the second dataset. In Fig. 6 the overbought mode has been pointed in the periods of; $23^{\text {rd }}$ to $25^{\text {th }}$ July $2018,16^{\text {th }}$ August $2018,2^{\text {nd }}$ to $5^{\text {th }}$ December $2018,16^{\text {th }}$ to $19^{\text {th }}$ December $2018,2^{\text {nd }}$ to $3^{\text {rd }}$ January 2019.

In this dataset the periods of; $9^{\text {th }}$ to $10^{\text {th }}$ July $2017,20^{\text {th }}$ November $2017,22^{\text {nd }}$ November $2017,27^{\text {th }}$ to $29^{\text {th }}$ May 2018, and $9^{\text {th }}$ to $20^{\text {th }}$ September - have been shown as in oversold conditions.

\section{Bollinger Bands (BBands) Indicator}

BBands indicator is used in order to compute the volatility in the proposed market. It also applied in order to determine the conditions of overbought and oversold of the market. BBands indicator has three lines, where the middle band represented by the simple moving average of the price for a specific period. The upper and lower lines are the standard deviations of the target prices and they are able to capture up to $95 \%$ of a security's price movement and perfect channel for capturing volatility. It is known that the market is highly volatile when the lower band and upper band close together and vice versa. The obtained results from applying BBands indicators over the used datasets are shown in Fig. 7 and 8 respectively.

BBands in $\mathrm{R}$ programing language is executed by applying BBands() function which has several different variables [22]. The first variable is known as data object which represent the data used in this experiment and contains the high, low, and close prices, while the second variable in BBands() function is the selected periods for moving averages for the data, and in this experiment is valued by 20 . The third variable in the function is the standard deviations number used in this experiment which is 2 standard deviations.

1) Al-Samaani factory for metal industries company: Fig. 7 shows the three lines obtained from applying the BBands indicator over the first dataset that used in this work. It is advised to wait for a stock to close less than the lower BBands to buy it in the following day, and this scenario not happing in this dataset. In $26^{\text {th }}$ to $27^{\text {th }}$ December 2018 the upper band and lower band are squeezed together, and this means the volatility is low. In such situation it is expected to the figure to move downside or upside.

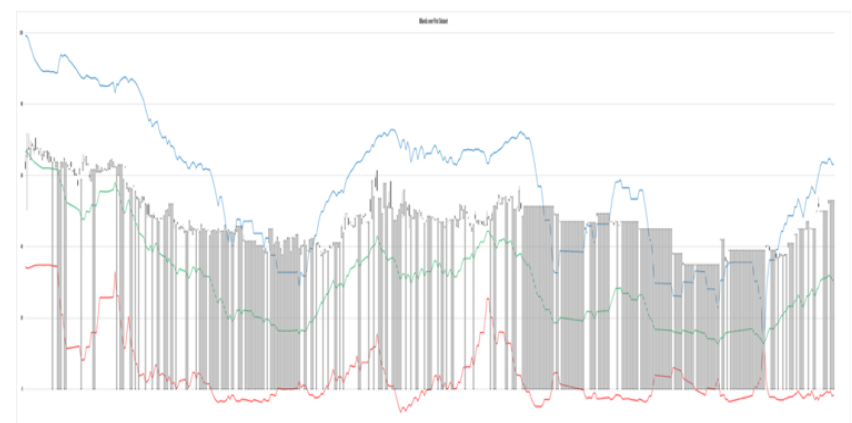

Fig. 7. Bollinger Bands (BBands) Indicator Over First Dataset.

2) Arab sea information system company: The results from applying the BBands indicator over the second dataset that used in this work are presented in Fig. 8. The two lines of the BBands (lower band line and upper band line) are squeezed in this dataset also in the period from $1^{\text {st }}$ to $5^{\text {th }}$ June 2017, and after this squeezed period the stock is go downside. Based on the theory of the indicator which is stated the following; the buy process is advised to be made after the stock to close less than the lower BBands. This scenario happens in the second dataset in the following dates; $18^{\text {th }}$ to $19^{\text {th }}$ April 2017, and $3^{\text {rd }}$ May 2017. The figure shows also that stock is less volatile in March and April.

\section{E. Aroon Indicator}

The indicator has been developed by Tushar Chande and the aim of this indicator is to be able to detect the start of the new trend in the market. The indicator is represented in percentage form between $0 \%$ to $100 \%$. Based on Aroon indicator, the uptrend is expected when the Aroon up line crosses over the Aroon-Down, and the downtrend is expected to be occurred when Aroon-Down crosses over the Aroon-Up. The results of applying Aroon indicator over the two datasets are shown in Fig. 9 and 10.

The Aroon indicator can be applied in $\mathrm{R}$ programing language by using aroon() function which is included in the TTR() package [22]. There are two arguments within the function; 1) the data object used in the experiment, and in this case the high and low prices are chosen to represent the data, and 2) the periods that has been used in the calculation of the indicator value, and it is selected in this case as 20 .

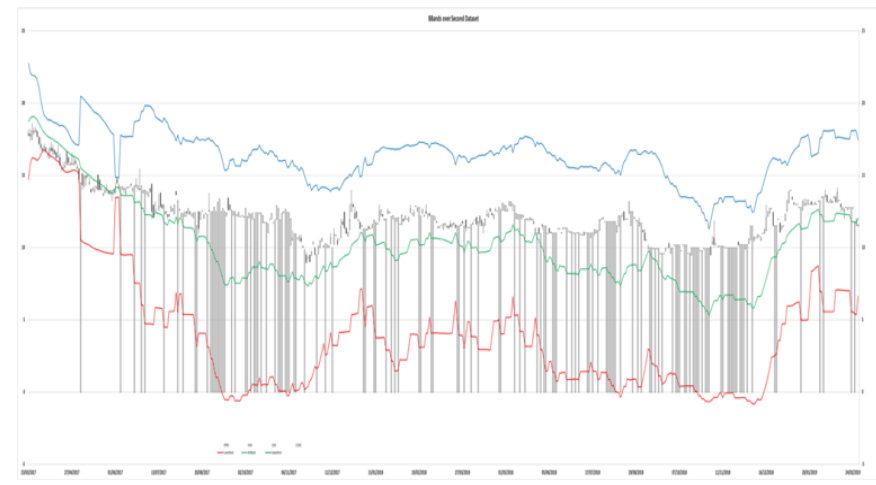

Fig. 8. Bollinger Bands (BBands) Indicator Over Second Dataset. 


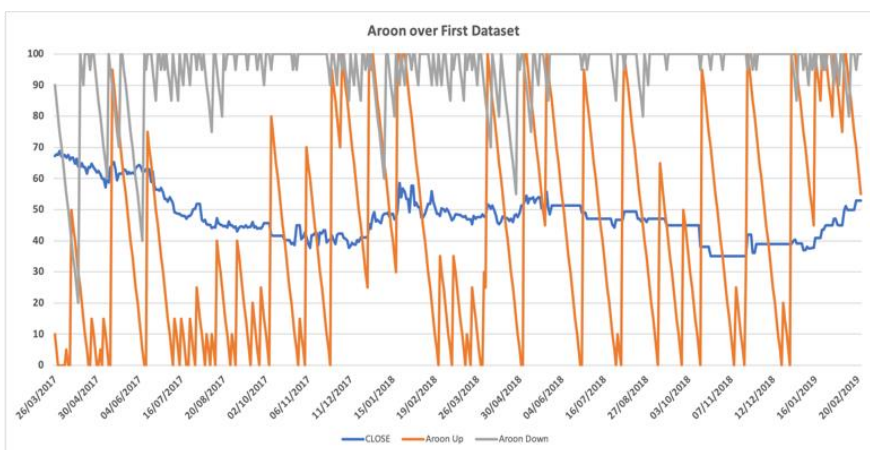

Fig. 9. Aroon Indicator over First Dataset.

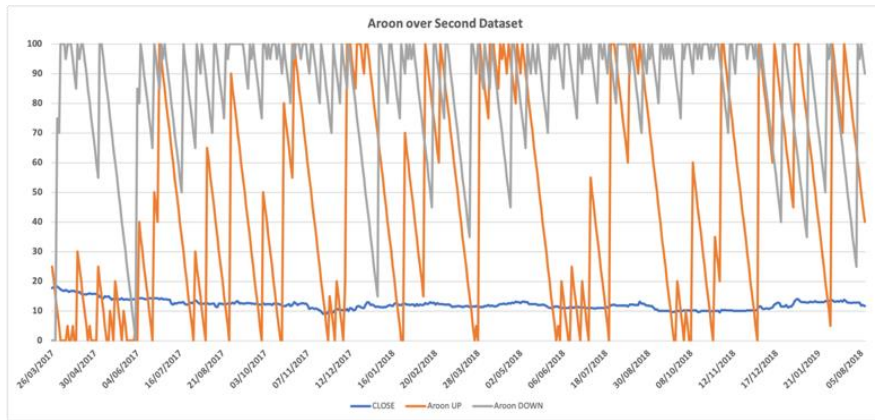

Fig. 10. Aroon Indicator over Second Dataset.

1) Al-Samaani factory for metal industries company: When the value of Aroon Up range between 0 to 30 and value of Aroon Down range between 70 to 100, the downtrend is excepted of the stock price. This scenario is shown in Fig. 9 as the price of the stock market moves down starting from $26^{\text {th }}$ February to $10^{\text {th }}$ December 2017 and during this period the Aroon Down reaches 100 and in most cases ranges between 70 to 100 , while the value of Aroon Up range was between 0 and 30. The stock market start trending up from $11^{\text {th }}$ December 2017 to $31^{\text {st }}$ January 2018. The Aroon indicator catches this uptrend as the Aroon Up line crosses over Aroon Down line.

2) Arab sea information system company: The Aroon indicator catches the changes occur in the price of the market. This is clear in some cases as shown in Fig. 10 for example the period between beginning of December to end of December 2017 as the price is trending up and the Aroon Up crosses above Aroon Down. The second example as shown in Fig. 10 as the price is trending up when the Aroon Up crosses above Aroon Down in $29^{\text {th }}$ March to $2^{\text {nd }}$ April 2018.

\section{CONCLUSION AND Future Work}

Five different technical analysis indicators have been identified and analyzed in this study to focus on how these indicators can be used in order to understand the trading in the stock market by using $\mathrm{R}$ programing language. Added to this, the study will help the investors in the stock market in the importance of these technical analysis indicators for improving their knowledge and increasing investments returns. The study has been conducted over two real-data obtained from Saudi stock market (NOMU). The dataset was for two full years starting from 26th February 2017 to 24th February 2019. The future plan is to extend this work by applying the AI technology in predicting the future of the stock market in collaboration with the different technical analysis indicators.

\section{REFERENCES}

[1] https://www.tadawul.com.sa. [Accessed on 20th June 2019].

[2] R. Isidore. and P. Christie, "Fundamental analysis versus technical analysis-a comparative review", International Journal of Recent Scientific Research, 2018, Vol. 9, Issue, 1 (B), pp. 23009-23013.

[3] V. Drakopoulou. "A review of fundamental and technical stock analysis technique". Journal of Stock \& Forex Trading, 2015, 5(1), 1-8.

[4] A. Suresh. "A study on fundamental and technical analysis". International Journal of Marketing, Financial Services \& Management Research, 2013, 2(5), 44-59.

[5] A. Lo, H. Mamaysky, and J. Wang. "Foundations of technical analysis: computational algorithms, statistical inference, and empirical implementation". The Journal of Finance, 2000, 55(4), 1705-1765.

[6] S. Jakpar, M. Tinggi, A. Hisham, and C. Wen, "Fundamental Analysis VS Technical analysis: The Comparison of Two Analysis in Malaysia Stock Market", UNIMAS Review of Accounting and Finance, 2018, Vol 1 No. 1.

[7] S. Mitra. "Usefulness of moving average based trading rules in India". International Journal of Business and Management, 2011, 6(7), 199-206.

[8] https://www.r-project.org, [Accessed on $20^{\text {th }}$ June 2019].

[9] Y. Wang and H. Deng, "Expectations, Behavior, and Stock Market Volatility", Emerging Markets Finance \& Trade, 2018, 54:3235-3255, DOI: https://doi.org/10.1080/1540496X.2018.1498331.

[10] P. Pai and C. Lin, "A hybrid ARIMA and support vector machines model in stock price forecasting" Omega, 2005, vol. 33, pp. 497-505.

[11] J. Wang, J. Wang, Z. Zhang, and S.. Guo, "Stock index forecasting based on a hybrid model," Omega, 2012, vol. 40, pp. 758-766.

[12] L. Wei, "A hybrid model based on ANFIS and adaptive expectation genetic algorithm to forecast TAIEX,"' Econ. Model., 2013, vol. 33, pp. 893-899.

[13] A. Atkins, M. Niranjan, and E. Gerding, "Financial news predicts stock market volatility better than close price", The Journal of Finance and Data Science, 2018, Volume 4, Issue 2. Pp 120-137. https://doi.org/10.1016/j.jfds.2018.02.002.

[14] K. Kannan, P. Sekar, M. Sathik and P. Arumugam, "Financial stock market forecast using data mining Techniques", Proceeding of the international MultiConfernece of Engineers and Computer Scientists 2010, Vol I, IMECS 2010, March 17-19, Hong Kong.

[15] S. Olaniyi, A. Kayode, and G. Jimoh. "Stock Trend Prediction Using Regression Analysis - A Data Mining Approach". ARPN Journal of Systems and Software, 2011, Volume 1 No. 4.

[16] A. Adebiyi, A. Adewumi, C. Ayo, "Stock price prediction using the ARIMA model", 16th IEEE International Conference on Computer Modelling and Simulation (UKSim), 2014, pp. 106 -112.

[17] J. Vaiz and M. Ramaswami, "Forecasting Stock Trend Using Technical Indicators with R", International Journal of Computational Intelligence and Informatics, 2016, Vol. 6: No. 3.

[18] C. Kirkpatrick, and J. Dahlquist, "Technical Analysis: The Complete Resource for Financial Market Technicians" FT Press; 3 edition, 2015.

[19] F. Labs. "FM Labs Indicator Reference". Retrieved from http://www.fmlabs.com/reference. [Accessed on 20 $0^{\text {th }}$ June 2019].

[20] William Blau, "Momentum, Direction, and Divergence", Wiley Trader's Exchange Book, 2008, $1^{\text {st }}$ Edition.

[21] J. Wilder, "New Concepts in Technical Trading Systems", Trend Research, 1978.

[22] https://www.rstudio.com/, [Accessed on 20 $0^{\text {th }}$ June 2019] 